\title{
BMJ Open Willingness of patients to use unused medication returned to the pharmacy by another patient: a cross-sectional survey
}

\author{
Charlotte Bekker, ${ }^{\oplus 1,2}$ Bart van den Bemt, ${ }^{1,3}$ Toine CG Egberts, ${ }^{2,4}$ Marcel Bouvy, ${ }^{4}$ \\ Helga Gardarsdottir $2,4,5$
}

To cite: Bekker $C$, van den Bemt B, Egberts TCG, et al. Willingness of patients to use unused medication returned to the pharmacy by another patient: a crosssectional survey. BMJ Open 2019;9:e024767. doi:10.1136/ bmjopen-2018-024767

- Prepublication history for this paper is available online. To view these files, please visit the journal online (http://dx.doi. org/10.1136/bmjopen-2018024767).

Received 14 June 2018 Revised 15 January 2019 Accepted 26 February 2019

Check for updates

(c) Author(s) (or their employer(s)) 2019. Re-use permitted under CC BY-NC. No commercial re-use. See rights and permissions. Published by BMJ.

For numbered affiliations see end of article.

Correspondence to

Dr Toine CG Egberts

a.c.g.egberts@uu.nl

\section{ABSTRACT}

Objectives Redispensing by pharmacies of medication unused by another patient could contribute to optimal use of healthcare resources. This study aimed to assess patient willingness to use medication returned by another patient and patient characteristics associated with this willingness.

Design Cross-sectional survey.

Setting A total of 41 community and 5 outpatient pharmacies in the Netherlands.

Participants Total of 2215 pharmacy visitors.

Primary and secondary outcome measures Patients completed a questionnaire regarding their willingness to use medication returned unused to the pharmacy by another patient, assuming quality was guaranteed. Secondary outcome measures included patient sociodemographic characteristics that were associated with patient willingness, analysed using logistic regression analysis and reported as ORs with $95 \% \mathrm{Cls}$.

Results Of the 2215 patients (mean (SD) age 50.6(18.0) years; $61.4 \%$ female), $61.2 \%$ were willing to use medication returned unused to the pharmacy by another patient. Patients who were unwilling mostly found it risky. Men were more willing to use returned medication (OR 1.3 $95 \% \mathrm{Cl} 1.1$ to 1.6), as did patients with a high educational level (OR $1.895 \% \mathrm{Cl} 1.3$ to 2.5$)$, those who regularly use 1-3 medications (OR $1.395 \% \mathrm{Cl} 1.1$ to 1.7), those who returned medication to the pharmacy for disposal (OR $1.595 \% \mathrm{Cl} 1.0$ to 2.3 ) and those who ever had unused medication themselves (OR $1.395 \% \mathrm{Cl} 1.1$ to 1.6)). Patients with non-Dutch cultural background were less willing to use returned medication (OR $0.395 \% \mathrm{Cl} 0.3$ to 0.4)).

Conclusions When quality is guaranteed, a substantial proportion of patients are willing to use medication returned unused to the pharmacy by another patient. This suggests that implementation of redispensing may be supported by patients.

\section{INTRODUCTION}

Up to one-third of patients do not use all medication dispensed by their pharmacy, ${ }^{12}$ leading to a waste of healthcare resources and potentially environmental pollution. Previous studies reported that $20 \%-90 \%$ of medication dispensed but unused by patients still are in their unopened and intact

\section{Strengths and limitations of this study}

This study included a large patient sample to assess their willingness to use redispensed medication.

- Patient groups who were more or less willing were identified.

- Patient willingness may not be identical if redispensing is implemented in practice.

- In-depth information on patient barriers and facilitators were not identified.

packaging. ${ }^{3-7}$ Patients either dispose these unused medication at home (eg, household waste) or return these to pharmacies who discard these as special waste. ${ }^{8}$ Redispensing these unused medication could contribute to waste-reduction. Although medication that remain unused by patients in healthcare institutions are occasionally redispensed to patients who cannot afford healthcare, ${ }^{9}{ }^{10}$ there is no standard practice, ${ }^{11}$ primarily due to uncertainties surrounding the quality assurance of returned medication and legal constraints including product liability.

Stakeholders are positive regarding implementation of a redispensing process ${ }^{12} 13$ however, they explicitly stated that successful implementation relies heavily on patient support. A qualitative study with 19 participants from the UK showed that people would generally agree to use redispensed medication if safety and product quality is guaranteed. ${ }^{14}$ Other surveys from the UK and the Netherlands showed that people would accept redispensed medication. ${ }^{15-17}$ However, these studies involved small study populations and did not determine which patient groups would be more or less willing to use redispensed medication. This study therefore aims to assess patient willingness to use medication returned unused to the pharmacy by another patient and patient characteristics associated with this willingness. 


\section{METHODS}

A cross-sectional anonymous survey was conducted in 41 community pharmacies and five outpatient pharmacies, involved in the Utrecht Pharmacy Practice network for Education and Research (UPPER) network of the Utrecht University, ${ }^{18}$ between April and December 2014 in the Netherlands (approved by the UPPER Institutional Review Board of the Utrecht University (UP1408)).

In each participating pharmacy, approximately consecutive 50 adult $(\geq 18$ years and able to communicate in Dutch) visitors were approached by pharmacy students to complete a questionnaire in writing while waiting or orally in case of returning medication for disposal. Visitors were asked about their willingness to use medication returned unused to the pharmacy by another patient if the quality was guaranteed, with multiple answer options: 'yes, it is a shame to destroy good-quality medication'; 'yes, if this medication is cheaper or free'; 'no, I don't want secondhand medication'; 'no, I find it risky' or 'other'. Besides registering their sociodemographic characteristics age, gender, educational level ('low'/'medium' /'high') and cultural background ('Dutch'/'other'), visitors were asked whether they had ever had unused medication themselves ('yes'/'no'/'don't know'), and the number of prescription medications they regularly use ('none'/' $1-3{ }^{\prime} /{ }^{\prime} \geq 4$ '). The questionnaire was composed through discussion with the research group, pilot tested among patients in two community pharmacies on inclusion and patients' understanding. It was feasible to include 50 patients per pharmacy per day and no adjustments to the questionnaire were made. The questionnaire was also used in another study that assessed unused medication returned to community pharmacies. Participating patients who were returning unused medication for disposal were asked additional questions as part of a larger study. ${ }^{7}$

Data were presented in proportions or means with SD. Associations between patient characteristics and willingness to use returned medication (answers categorised into yes/no) were analysed in STATA V.13, using univariate and multivariate logistic regression analyses (full model with complete cases), reported as ORs with $95 \%$ CIs. To assess if hierarchical data structure (patients clustered within pharmacy) influenced our outcomes, multilevel sensitivity analysis was conducted.

\section{Patient involvement}

Patients were not involved in the design of the study.

\section{RESULTS}

A total of 2215 patients (mean (SD) age 50.6 (18.0) years, $61.4 \%$ female) participated, $88.8 \%$ of whom were community pharmacy visitors. Of all patients, 142 (6.4\%) were returning medication for disposal. Most patients had a Dutch cultural background (77.8\%), a medium educational level $(48.2 \%)$ and regularly used $1-3$ prescription
Table 1 Patient willingness to use medication returned unused to the pharmacy by another patient

\begin{tabular}{lc}
\hline & $\begin{array}{l}\text { Patients } \\
\mathbf{n = 2 2 1 5}(\mathbf{n}, \mathbf{\%})\end{array}$ \\
\hline Willing* $^{*}$ & $1355(61.2)$ \\
$\begin{array}{l}\text { Yes, it is a shame to destroy good-quality } \\
\text { medication }\end{array}$ & $1198(88.4)$ \\
Yes, if this medication is cheaper or free & $269(19.9)$ \\
\hline Other & $35(2.6)$ \\
Unwilling* & $869(39.2)$ \\
No, I find it risky & $557(64.1)$ \\
No, I don't want secondhand medication & $357(41.1)$ \\
Other & $8(0.9)$ \\
\hline
\end{tabular}

*Patients could report multiple answers.

medications (45.9\%). A total of $1436(64.8 \%)$ patients had ever had unused medication themselves.

Over half of patients were willing to use medication returned unused to the pharmacy by another patient $(61.2 \%$, table 1$)$. Of these, $88.4 \%$ was willing because they found it a shame to destroy good-quality medication and $19.9 \%$ if these were cheaper or free. Some patients explicitly reported that they were only willing if these were returned in original, unopened packages. Of patients who were not willing to use returned medication, most found it risky $(64.1 \%)$ or did not wanted secondhand medication $(41.1 \%)$. Other reasons included not knowing how medication were handled and stored by other patients and how quality could be monitored.

Men were more willing to use returned medication (OR $1.395 \%$ CI 1.1 to 1.6), as did patients with a high educational level (OR 1.8 95\% CI 1.3 to 2.5, table 2). Furthermore, patients who regularly use $1-3$ prescription medications were more willing to use returned medication (OR $1.395 \%$ CI 1.1 to 1.7 ), also patients who were questioned as they returned medication (OR $1.595 \%$ CI 1.0 to 2.3 ) and patients who had ever had unused medication themselves (OR $1.395 \%$ CI 1.1 to 1.6). Patients with non-Dutch cultural background were less willing to use returned medication (OR $0.395 \% \mathrm{CI} 0.3$ to 0.4 ). Age and type of pharmacy were not associated with patient willingness to use returned medication. Sensitivity analysis demonstrated similar associations.

\section{DISCUSSION}

This study shows that a substantial proportion of patients are willing to use medication returned to the pharmacy by another patient when the quality is guaranteed. Males, patients with a high education, those regularly using medication, those returning medication to the pharmacy for disposal and those who ever had unused medication themselves were in particular more willing to use returned medication. 
Table 2 Patient characteristics associated with willingness to use medication returned by another patient $\left(n=2136^{\star}\right)$

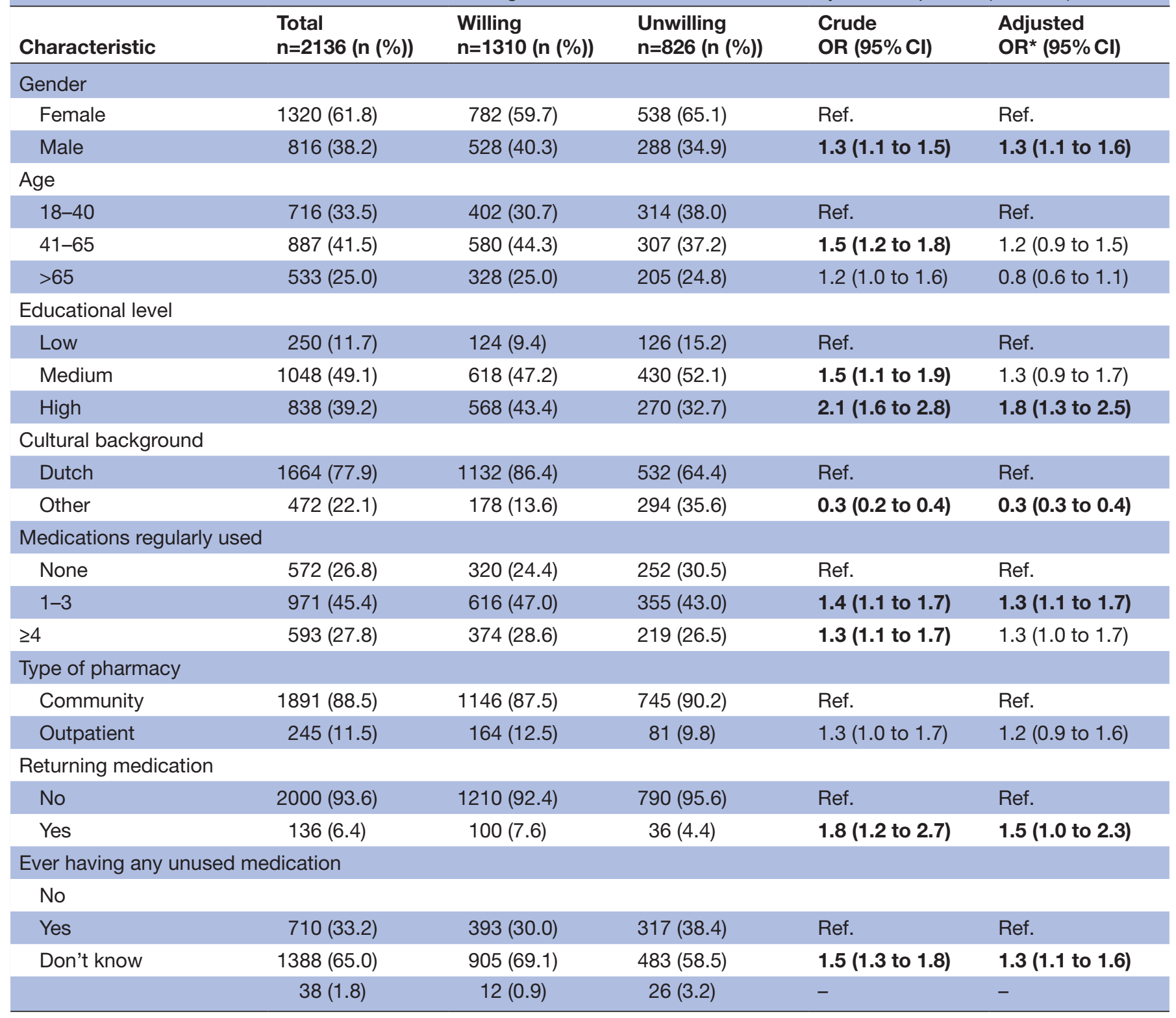

Significant associations are shown in bold.

*Multivariate logistic regression analysis was conducted.

†For 79 (3.6\%) patients, sociodemographic data was missing. Associations between patient characteristics and willingness to use returned medication were analysed for the remaining 2136 patients.

Worldwide, increased attention is being paid to sustainable environment, including green pharmacy practices, of which redispensing represents an important component. ${ }^{19}$ Patient support for redispensing is crucial. ${ }^{12} 13$ Our findings in a large patient sample are consistent with previous, smaller, studies, which found that 50\%-95\% of patients would accept medication returned by other patients. ${ }^{15-17}$ We found that patients who were less supportive primarily had concerns about risks, including tampering with the medication, inadequate storage conditions and reliability of the quality assurance. Few studies have identified patient barriers and facilitators to redispensing unused medication by pharmacies. Almahad et $a l^{14}$ interviewed 19 patients $\geq 40$ years and concluded that many are in favour of redispensing because it could reduce the negative consequences of waste. Potential disadvantages identified by these patients included improper storage of medication, medication errors introduced by patients and counterfeit medication entering the system. We found that less willing patients had more often non-Dutch cultural backgrounds. Before considering implementation of redispensing, concerns of less willing patients should be identified in-depth and barriers should be overcome. Interventions aiming at behavioural changes may be required for ultimately increasing patient support, such as raising awareness on waste and using (monetary) incentives. Future studies should also identify the type of medication packages that can be redispensed 
from a patient perspective, for instance, original manufacturer's packaging or also single blisters.

Although patients were found supportive of redispensing, implementation may not be cost-beneficial for all types of medication. In a micro-costing study, all pharmacy's additional process steps that are required to redispense unused medication in the pharmacy, including direct (labour and material) and indirect costs, were quantified (Bekker, accepted) ${ }^{20}$. The outcomes showed that redispensing is most cost-beneficial if applied to expensive medication. For low-cost medication, paying for the additional processing to guarantee the quality of returned medication will not outweigh the additional costs. To this end, redispensing may only be implemented for expensive medication. However, these substantially contribute to pharmaceutical spending, and if patients discontinue therapy frequently unused, expensive medication remains unused. ${ }^{3}$ Implementing a redispensing process for expensive medication could lead to substantial cost savings.

Some patients were only willing to use redispensed medication if this were for cheaper or for free. Barriers may arise at providing redispensed medication at lower cost, because this may implicate a lower quality and could lead to lower adherence. Furthermore, if medications are provided at lower cost this will also influence the cost-benefit ratio, that will presumably increase, thereby lowering the types of medications that can be redispensed from an economical point of view.'

Concerns exist about increased risk of counterfeit medication entering the pharmaceutical supply and use chain during redispensing. ${ }^{14}$ This will be tackled by the European Union directives 2011/62/EU and EU2016/161, which demand that manufacturers add tamper indicators and unique identification codes to the outer packaging of medication from 2019 to minimise the risk of falsification. Each unique package will be registered in a large repository, then during the dispensing to the patient its authenticity will be verified and the package will be unsubscribed from the database. Unfortunately, this directive will likely hamper redispensing, as returned medication cannot re-enter the database and thus cannot be verified during the subsequent redispensing. How to tackle this barrier should be further explored. For example, authorised persons such as pharmacists may be able to re-subscribe returned medication into the database.

This study captured the willingness on redispensing in a large patient sample. However, we cannot assure that this is identical if implemented in practice. No information on the number of patients who refused to participate was registered and therefore the response rate is unknown. Consequently, no conclusions can be drawn regarding patients' general willingness to participate in a study on medication waste. Furthermore, pharmacy visitors may not be representative of the general population; however, they may well reflect the most likely people to receive returned medication. Lastly, patients who returned medication to community pharmacies for disposal were interviewed $(n=142,6.4 \%)$ and were found more willing to use redispensed medication compared with patients who answered in writing. These patients may have given what they considered to be socially desirable answers, and were briefly informed on the potential consequences of medication waste. Additionally, these patients may be more willing to discuss medication waste and possibilities for redispensing than patients who refused to participate, which may overestimate the outcomes.

\section{CONCLUSIONS}

A substantial proportion of patients are willing to use medication returned unused to the pharmacy by another patient when the quality is guaranteed, suggesting that implementation of redispensing may be supported by patients.

\section{Author affiliations}

${ }^{1}$ Department of Pharmacy, Sint Maartenskliniek, Nijmegen, The Netherlands ${ }^{2}$ Division Laboratories and Pharmacy, Department of Clinical Pharmacy, University Medical Centre, Utrecht, The Netherlands

${ }^{3}$ Department of Pharmacy, Radboud University Medical Centre, Nijmegen, The Netherlands

${ }^{4}$ Division Pharmacoepidemiology and Clinical Pharmacology, Faculty of Science, Utrecht Institute for Pharmaceutical Sciences, Utrecht, The Netherlands

${ }^{5}$ Faculty of Pharmaceutical Sciences, University of Iceland, Reykjavik, Iceland

Acknowledgements The authors want to thank all the pharmacies that participated in this study and all the students who collected the data. Special thanks to Salma Boudhan and Fatima Elouanajni who facilitated the coordination and data collection of the study.

Contributors $\mathrm{CB}, \mathrm{BvdB}, \mathrm{TCGE}, \mathrm{MB}$ and $\mathrm{HG}$ contributed to conception and design of the study. Students collected the data, which was supervised by MB, HG and CB. CB was a major contributor in analysis and interpretation of the data and in writing the manuscript. BvdB, TCGE, MB and HG contributed data interpretation, and revision and approval of the final manuscript.

Funding The authors have not declared a specific grant for this research from any funding agency in the public, commercial or not-for-profit sectors.

Competing interests None declared.

Patient consent for publication Not required.

Provenance and peer review Not commissioned; externally peer reviewed.

Data sharing statement Data used in the current study are available from the corresponding author on reasonable request.

Open access This is an open access article distributed in accordance with the Creative Commons Attribution Non Commercial (CC BY-NC 4.0) license, which permits others to distribute, remix, adapt, build upon this work non-commercially, and license their derivative works on different terms, provided the original work is properly cited, appropriate credit is given, any changes made indicated, and the use is non-commercial. See: http://creativecommons.org/licenses/by-nc/4.0/.

\section{REFERENCES}

1. Reitsma M, Brabers A, Korevaar J, et al. One third of the medicine users has medicines left unused [Dutch]. NIVEL 2013.

2. Trueman P, Lowson K, Blighe A, et al. Evaluation of the Scale, Causes and Costs of Waste Medicines: London, 2010.

3. Bekker CL, Melis EJ, Egberts ACG, et al. Quantity and economic value of unused oral anti-cancer and biological disease-modifying anti-rheumatic drugs among outpatient pharmacy patients who discontinue therapy. Res Social Adm Pharm 2019;15:100-5.

4. Mackridge AJ, Marriott JF. Returned medicines: waste or a wasted opportunity? J Public Health 2007;29:258-62. 
5. Toh MR, Chew L. Turning waste medicines to cost savings: a pilot study on the feasibility of medication recycling as a solution to drug wastage. Palliat Med 2017;31:35-41.

6. Vogler S, de Rooij R. Medication wasted - Contents and costs of medicines ending up in household garbage. Res Social Adm Pharm 2018;14:1140-6.

7. Bekker CL, van den Bemt BJF, Egberts ACG, et al. Patient and medication factors associated with preventable medication waste and possibilities for redispensing. Int $J$ Clin Pharm 2018;40:704-11.

8. Paut Kusturica M, Tomas A, Sabo A. Disposal of unused drugs: Knowledge and behaviour among people around the world. Rev Environ Contam Toxicol 2017;240:71-104.

9. Supporting Initiatives to Redistribute Unused Medicine: SIRUM, 2014. www.sirum.org [Accessed 23 Mar 2018].

10. Drug Recycling - Utilization of Unused Prescription Drugs Act. Tusla Cty Med Soc http://tcmsok.org/drug-recycling/ [Accessed 19 Mar 2018].

11. Bekker C, Gardarsdottir H, Egberts A, et al. Pharmacists' activities to reduce medication waste: an international survey. Pharmacy 2018:6:94-14.

12. Bekker CL, Gardarsdottir H, Egberts TC, et al. Redispensing of medicines unused by patients: a qualitative study among stakeholders. Int J Clin Pharm 2017;39:196-204.
13. McRae D, Allman M, James D. The redistribution of medicines: could it become a reality? Int J Pharm Pract 2016;24:411-8.

14. Alhamad H, Patel N, Donyai P. How do people conceptualise the reuse of medicines? An interview study. Int J Pharm Pract 2018;26:232-41.

15. Hendrick A, Baqir W, Barrett S, et al. Prescribing Mrs Smith's Medication To Mr Jones: The Views Of Patients And Professionals On The Reuse Of Returned Medicines. Pharm Manag 2013;29:25-6.

16. NHS. NHS Sustainable Development Unit (SDU) Survey. Topline Results and Summary Report December 2011, 2011.

17. de Jong MJ, Pierik MJ, Peters A, et al. Exploring conditions for redistribution of anti-tumor necrosis factors to reduce spillage: A study on the quality of anti-tumor necrosis factor home storage. $J$ Gastroenterol Hepatol 2018;33:426-30.

18. Koster ES, Blom L, Philbert D, et al. The Utrecht Pharmacy Practice network for Education and Research: a network of community and hospital pharmacies in the Netherlands. Int $J$ Clin Pharm 2014;36:669-74.

19. FIP. Green pharmacy practice: Taking responsibility for the environmental impact of medicines. The Hague: International Pharmaceutical Federation, 2015.

20. Bekker CL, Gardarsdottir H, Egberts ACG, et al. What does it cost to redispense unused medications in the pharmacy? A micro-costing study. BMC Health Serv Res 2019;19:243. 